\title{
Advanced Reactor Technology Program Molten Salt Reactor Campaign FY 2018 Summary
}

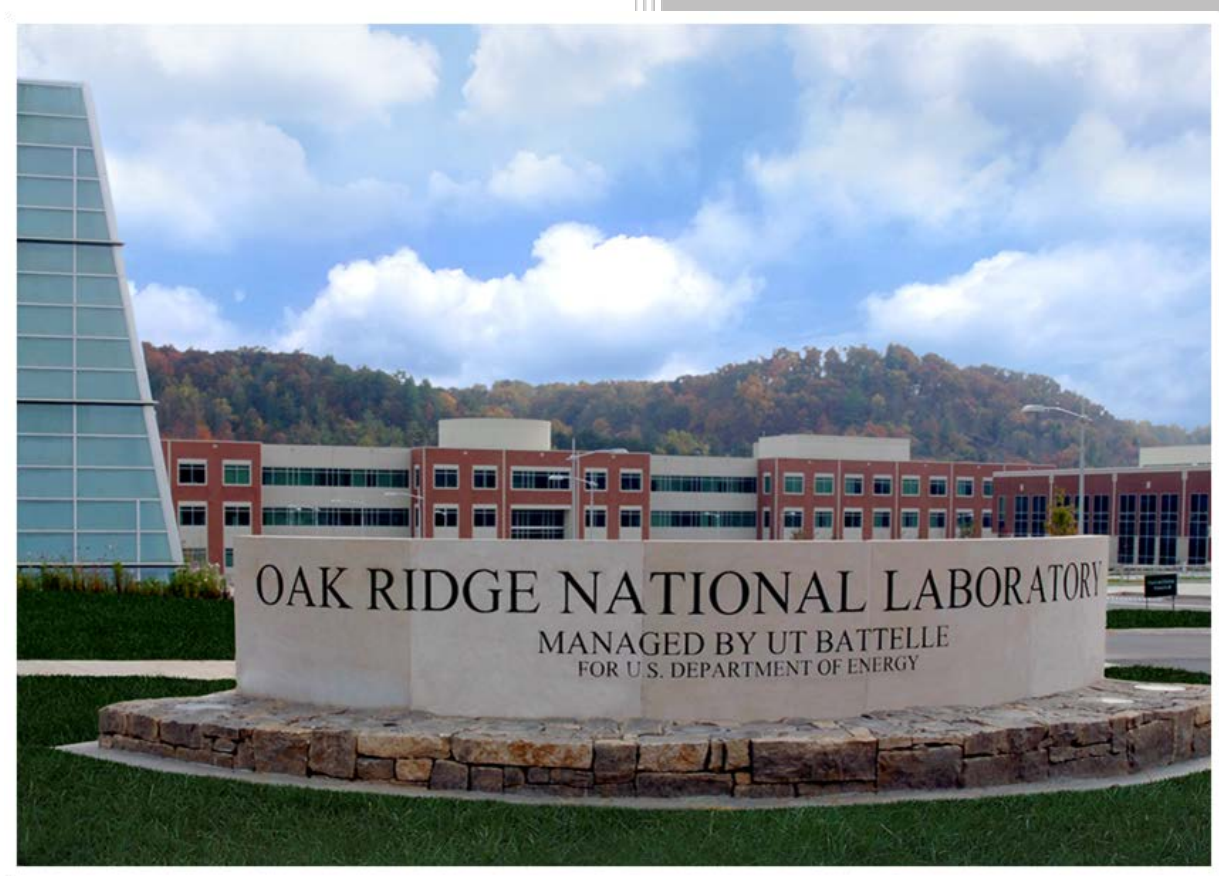

Approved for public release. Distribution is unlimited.

A. L. Qualls

September 2018 


\title{
DOCUMENT AVAILABILITY
}

Reports produced after January 1, 1996, are generally available free via US Department of Energy (DOE) SciTech Connect.

\section{Website www.osti.gov}

Reports produced before January 1, 1996, may be purchased by members of the public from the following source:

\author{
National Technical Information Service \\ 5285 Port Royal Road \\ Springfield, VA 22161 \\ Telephone 703-605-6000 (1-800-553-6847) \\ TDD 703-487-4639 \\ Fax 703-605-6900 \\ E-mail info@ntis.gov \\ Website http://classic.ntis.gov/
}

Reports are available to DOE employees, DOE contractors, Energy Technology Data Exchange representatives, and International Nuclear Information System representatives from the following source:

Office of Scientific and Technical Information

PO Box 62

Oak Ridge, TN 37831

Telephone 865-576-8401

Fax 865-576-5728

E-mail reports@osti.gov

Website http://www.osti.gov/contact.html

This report was prepared as an account of work sponsored by an agency of the United States Government. Neither the United States Government nor any agency thereof, nor any of their employees, makes any warranty, express or implied, or assumes any legal liability or responsibility for the accuracy, completeness, or usefulness of any information, apparatus, product, or process disclosed, or represents that its use would not infringe privately owned rights. Reference herein to any specific commercial product, process, or service by trade name, trademark, manufacturer, or otherwise, does not necessarily constitute or imply its endorsement, recommendation, or favoring by the United States Government or any agency thereof. The views and opinions of authors expressed herein do not necessarily state or reflect those of the United States Government or any agency thereof. 
Reactor and Nuclear Systems Division

\title{
Advanced Reactor Technology Program Molten Salt Reactor Campaign FY 2018 Summary
}

\author{
A. L. Qualls
}

Date Published: September 2018

Prepared by

OAK RIDGE NATIONAL LABORATORY

Oak Ridge, TN 37831-6283

managed by

UT-BATTELLE, LLC

for the

US DEPARTMENT OF ENERGY

under contract DE-AC05-00OR22725 



\section{CONTENTS}

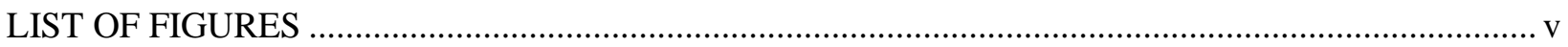

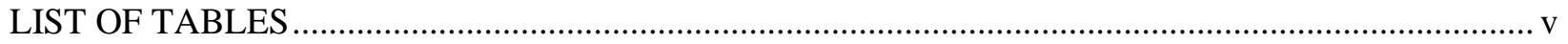

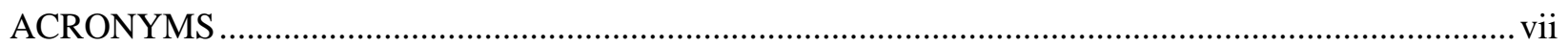

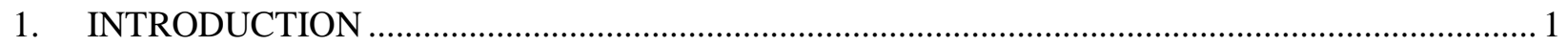

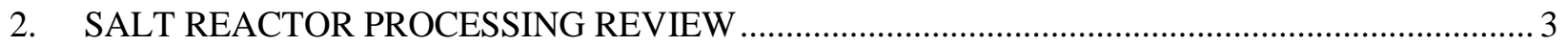

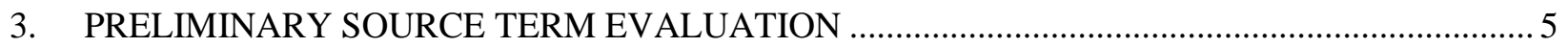

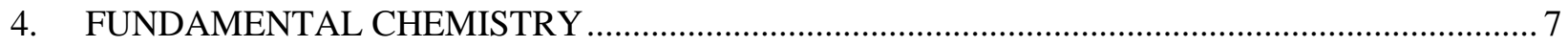

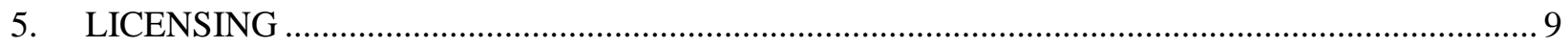

5.1 MAJOR ELEMENTS OF SAFETY AND LICENSING ROADMAP FOR MOLTEN

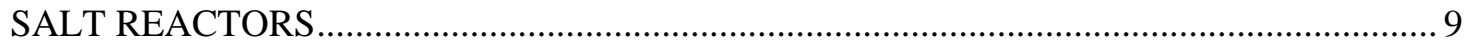

5.2 SUMMARY OF MAJOR FINDINGS FROM PROPOSED NUREG-1537 UPDATE ........... 10

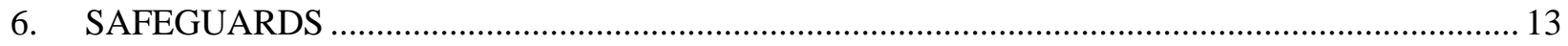

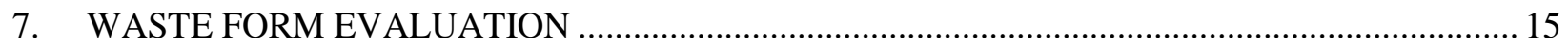

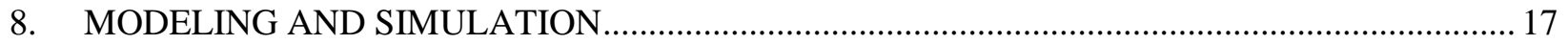

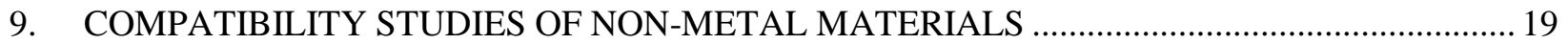

9.1 STATIC CAPSULE EXPOSURES OF SALTS AND STRUCTURAL MATERIALS ........... 19

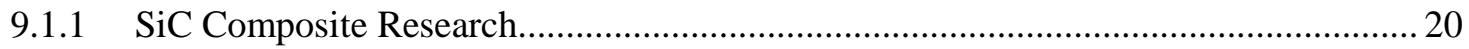

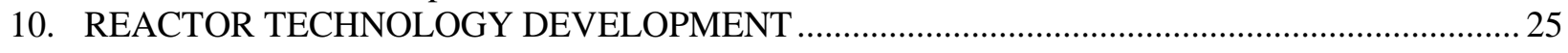

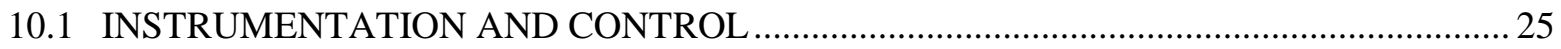

10.2 HIGH TEMPERATURE FISSION CHAMBER: THE OHIO STATE UNIVERSITY

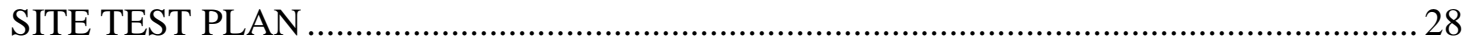

10.2.1 Experimental Results of the High-Temperature Fission Chamber Testing in a

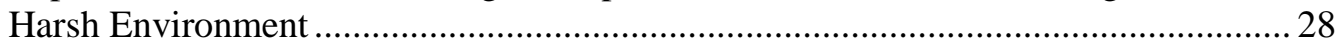

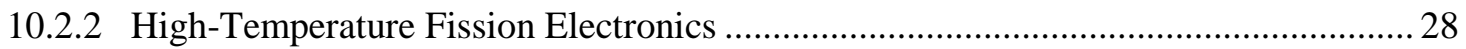

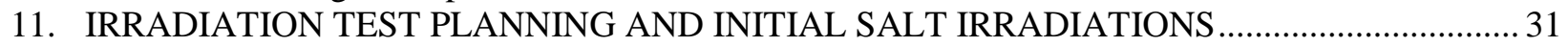

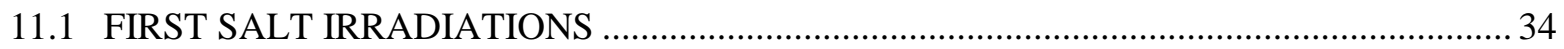





\section{LIST OF FIGURES}

Figure 1. List of various graphite grades and their characteristics......................................................... 20

Figure 2. Images of the specimens that have been prepared: (a) SiC monolith specimen with a smooth surface and (b) SiC composite specimen.

Figure 3. Images of the exposed SiC CVD specimen (a) polished shiny surface and (b) the unpolished dull surface.

Figure 4. Cross-section view of the MITR core.

\section{LIST OF TABLES}

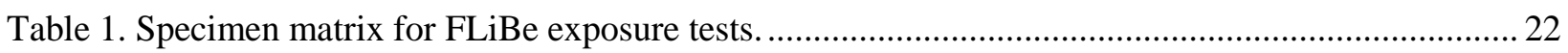

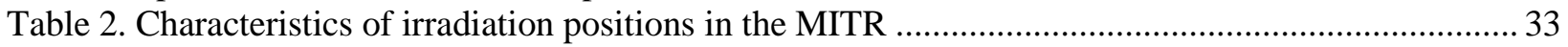

Table 3. Characteristics of selected irradiation positions in the OSURR. .............................................. 34 



\section{ACRONYMS}

$\begin{array}{ll}\text { ANL } & \text { Argonne National Laboratory } \\ \text { ART } & \text { Advanced Reactor Technology } \\ \text { CVD } & \text { chemical vapor deposition } \\ \text { CVI } & \text { chemical vapor infiltration } \\ \text { DOE } & \text { US Department of Energy } \\ \text { EDS } & \text { energy dispersive x-ray spectroscopy } \\ \text { FHR } & \text { fluoride salt-cooled high-temperature reactor } \\ \text { FLiBe } & \text { lithium fluoride-beryllium fluoride salt } \\ \text { FLiNaK } & \text { lithium fluoride-sodium fluoride-potassium fluoride } \\ \text { HEPA } & \text { high-efficiency particulate air } \\ \text { HTFC } & \text { High-Temperature Fission Chamber } \\ \text { I\&C } & \text { instrumentation and controls } \\ \text { INL } & \text { Idaho National Laboratory } \\ \text { LFMSR } & \text { liquid-fueled molten salt reactor } \\ \text { LWR } & \text { light water reactor } \\ \text { MCFR } & \text { molten chloride fast reactors } \\ \text { MITR } & \text { Massachusetts Institute of Technology Reactor } \\ \text { MSBR } & \text { Molten Salt Breeder Reactor } \\ \text { MSR } & \text { molten salt reactor } \\ \text { MSRE } & \text { Molten Salt Reactor Experiment } \\ \text { NE } & \text { Office of Nuclear Energy } \\ \text { NPP } & \text { nuclear power plant } \\ \text { NRC } & \text { US Nuclear Regulatory Commission } \\ \text { ORNL } & \text { Oak Ridge National Laboratory } \\ \text { OSURR } & \text { Ohio State University Research Reactor } \\ \text { PHTS } & \text { primary heat transport system } \\ \text { PNNL } & \text { Pacific Northwest National Laboratory } \\ \text { R\&D } & \text { research and development } \\ \text { SEM } & \text { scanning electron microscopy } \\ \text { special nuclear material } \\ \text { structures, systems, and components }\end{array}$





\section{INTRODUCTION}

In FY 2018, the inaugural Molten Salt Reactor (MSR) Campaign was begun with the US Department of Energy (DOE) Advanced Reactor Technology (ART) program. The campaign is led out of Oak Ridge National Laboratory (ORNL) under the direction of Lou Qualls, who serves as the national technical director for the program. The campaign is a revival and refocusing of a significant DOE research program from the 1950's, 1960's and 1970's, which culminated in the operation of the Molten Salt Reactor Experiment. The principal objectives of the campaign's first year were to study and define the current condition of the technology, identify and prioritize technology gaps, and establish a national team of experts to collaboratively address the technical needs. The highest-level objective of the campaign is to facilitate the development and near-term market deployment of MSRs in conjunction with industry partners.

To evaluate MSR technology and policy needs, a series of assessments were conducted in the areas of licensing, modeling and simulation, chemistry, instrumentation and control, and safeguards. The assessments were performed within the FY 2018 campaign to begin directing activities that were deemed to be impactful toward MSR development and to initiate collaborative arrangements with industry, universities, other DOE programs, and international bodies. Generally, the activities being performed are categorized as follows:

1. Generate data and produce chemistry models that predict the behavior of salts within the context of an operating reactor, including models for source term behavior in accident scenarios;

2. Develop information related to the understanding of salt behavior and its impact on reactor operation;

3. Work with the US Nuclear Regulatory Commission (NRC) to describe possible MSR licensing paths and needs, including those related to safeguards; and

4. Identify and develop technology that is considered essential or enabling for MSR success, including capabilities related to salt production, processing, and disposal, and technology related to the monitoring and control of MSRs and their effluent streams.

As part of the FY 2018 campaign, a team of researchers from national laboratories and universities has been assembled to collaborate in the areas of chemistry, salt handling, modeling, materials, and instrumentation. Together, these experts continue to assess the needs of the campaign and to plan and execute the research priorities within it.

The MSR campaign routinely interacts with industry stakeholders to ensure that the highest-priority needs for MSR development and deployment are being addressed. The intention is to establish a broad capability using the best expertise across the national laboratory system and throughout universities. The campaign had active collaboration with Idaho National Laboratory (INL), Argonne National Laboratory (ANL), and Pacific Northwest National Laboratory (PNNL) in FY 2018 and is expanding collaboration to include Sandia National Laboratories and Los Alamos National Laboratory in FY 2019. The campaign is actively working with the Materials Waste Form and Disposition campaign and is expanding collaboration with the Nuclear Energy Advanced Modeling and Simulation Program and the Materials Protection and Accountancy Campaigns in FY 2019.

Most liquid-fueled MSR concepts use fissile-bearing salts that are in solution with carrier salts that circulate throughout the primary system. Fission products and transmutation products are borne directly within the fuel and are not contained directly within a fixed, protective cladding. The salt is changing during operation and the principal technical concerns related to the changes in salt chemistry include the following: 
- Changes in neutronic performance which affect reactivity and plant dynamic performance

- Changes in thermophysical properties that occur over the life of the salt which may affect thermal hydraulics, including natural circulation and drain flow associated with off-normal operation

- Accident source term transport and distribution

- Changes in salt thermochemical properties which impact fissile material solubility, radionuclide vapor pressure, and corrosion

The behavior of fuel salts is complicated by a series of factors such as chemical and physical impurities, refueling, salt-conditioning, fission and fission products, and the possible dissolution of corrosion products. The chemical and transport behavior of salt constituents must be understood for all relevant reactor operating conditions, including periodic shutdown and severe accident conditions and possible freeze-thaw cycles. Salts must also be tested with materials to examine their compatibility. The allowable range of salt parameters must be understood. The methods to monitor salts and to adjust important parameters must be established. For fuel qualification and reactor licensing, it is necessary to study fuelsalt behavior under representative reactor conditions, including flux, temperature, pressure, and flow.

Among the challenges of developing reactor systems with liquid fuels is the development of regulatory practices associated with them. New policies will be informed by the science of salt research. Getting relevant data under irradiation, (and potentially all the way through conditions associated with accident scenarios), will be challenging. 


\section{SALT REACTOR PROCESSING REVIEW}

Report: INL/EXT-18-51033

Molten Salt Reactor Salt Processing-Technology Status

INL reviewed citations related to MSR development at ORNL and summarized them in a report that provides an overview of the engineering requirements of a chemical processing plant to support the Molten Salt Breeder Reactor (MSBR). The report includes descriptions of the unit operations and flowsheet development at ORNL. The transition from the two-fluid MSBR to the single-fluid MSBR was largely due to the development of new separations technologies for the management of uranium, protactinium, and fission products in fluoride molten salts. The development and refinement of chemical processing plant flowsheets continued throughout the entirety of the MSBR program at ORNL. A great deal of experimental and theoretical work was performed in support of the unit operations and flowsheets described in the report.

The report also summarizes the literature on thermo-physical properties and phase diagrams for salts (both fuel and coolant salts) considered for various designs discussed as part of MSR development at ORNL. In addition, properties for several salt mixtures (binary and ternary) identified for application as coolant salts for MSR, advanced high-temperature reactors, and other advanced reactor designs, have been included. The consolidated data help identify the current knowledge and gaps in the relevant literature for a particular system of interest.

MSBR and molten chloride fast reactors (MCFRs) could use the fuel from spent nuclear fuels. To recycle the spent nuclear fuels for preparing the fuels for MSBR and MCFR, two head-end processes, fluorination and chlorination, for reprocessing the spent nuclear fuels were reviewed. To make the fluoride salts for MSBR, most spent fuels, including uranium oxide, uranium nitride, and metal fuels, can be fluorinated by using fluorine gas $\left(\mathrm{F}_{2}\right)$ or other fluorinating gases such as $\mathrm{HF}, \mathrm{ClF}_{3}, \mathrm{BrF}_{3}, 2 \mathrm{NH}_{4} \mathrm{HF}_{2}$, and $\mathrm{NF}_{3}$. During the fluorination process, the volatile $\mathrm{UF}_{6}$ can be separated easily by chemical reaction between the spent fuel and a fluorination reagent, followed by sorption and then desorption. $\mathrm{UF}_{6}$ can be further easily reduced to the $\mathrm{UF}_{4}$ suitable for MSBR. To make the chloride salts for MCFR, the spent oxide fuels can be chlorinated (e.g., by $\mathrm{CCl}_{4}, \mathrm{COCl}_{2}, \mathrm{Cl}_{2}-\mathrm{CCl}_{4}$, or $\mathrm{NH}_{4} \mathrm{Cl}$; by $\mathrm{Cl}_{2}$ gas with carbon presence; or by $\mathrm{MoCl}_{5}$ ). $\mathrm{CCl}_{4}$ appears from the literature to be a widely used chlorination reagent. Due to the solid gas reaction characteristic, powders with higher surface areas were preferred for improving the efficiency and chlorination reaction kinetics. In recent years, by using noncorrosive $\mathrm{ZrCl}_{4}$ as chlorinating reagents and employing a liquid-phase chlorination process (e.g., $\mathrm{LiCl}-\mathrm{KCl}$ at $\left.500^{\circ} \mathrm{C}\right)$, the spent oxide fuels $\left(\mathrm{UO}_{2}\right.$, $\mathrm{PuO}_{2}$ ) were reportedly chlorinated effectively.

Materials corrosion (which is strongly affected by the molten salt chemistry, among others) is a significant issue and needs to be well controlled for long-term operation of an MSR. The purification of and materials corrosion in both fluoride and chloride salts are reviewed. Thanks to the Molten Salt Reactor Experiment (MSRE) program in 1960s and recent DOE-supported programs in fluoride salts (particularly lithium fluoride-beryllium fluoride [FLiBe] salt), a large database of molten salt chemistry (including salt purification and materials corrosion control) exists. The purification of the fluoride salt can be achieved by sparging with a mixture of $\mathrm{H}_{2}$ and $\mathrm{HF}$ gas followed by hydrogen sparging and filtering. A noncorrosive fluorination reagent was also reported for purification of fluoride salt. If the salt is controlled at a slightly reducing redox potential by controlling the $\mathrm{UF}_{4} / \mathrm{UF}_{3}$ ratio at a desired value, the corrosion of the candidate alloys such as Hastelloy N and 316SS is expected to be controlled.

The available data for corrosion of materials in chloride salts are limited, much less than the data for the corrosion of materials in fluoride salts. The purification of chloride salt is not as established as that of fluoride salt, and the oxide impurity in the chloride salt is more difficult to be removed by $\mathrm{HCl}$ sparging. Sparging with $\mathrm{CCl}_{4}$ gas is found to be much more effective than sparging with $\mathrm{HCl}$. To make highquality, impurity-free chloride salts, a standardized purification process is desired. Current results on the 
corrosion of materials in chloride salts are not consistent, probably due to different experimental conditions and the unknown impurity in the tested chloride salts. For example, the effects of chromium content in the alloy and temperature on the corrosion of materials in the chloride salts are not clear. An improved understanding of chloride salt corrosion mechanisms is needed. Further systematic study is also needed to identify the most suitable materials for long-term service in chloride fast reactors.

Attempts to adopt the electrochemical separation processes to the MSR system are relatively new and few published results on that effort are available. The motivation of this effort is that a well-designed electrochemical separation process for the treatment of the involved salt in the MSR can be beneficial in terms of cost, simplicity, and waste minimization. From the perspective of electrochemically treating the salt for separating undesirable constituents, the relative stability of salt species plays an important role. Ideally, one may want to have a salt system in which the least stable species, such as neutron poison fission products, are the ones that need to be separated. Thus, with a reactor system requiring the molten salt reprocessing to maintain reactor performance, the choice of the salt species allowing a simple separation process should be another important requirement. This requirement can be systematically approached by examining the relative stability of the candidate species expressed with the standard state free energy formation. Given the preliminary information on the relative stability of the salt species, the pertinent challenges associated with the treatment of the molten salt in supporting the MSR operation are discussed. 


\section{PRELIMINARY SOURCE TERM EVALUATION}

Report: ORNL/TM-2018/958

Thermochemical and Transport Properties Important to Molten Salt Reactor Operation: Off-Gas Performance under Normal Operation and Fission Product Mechanistic Source Term

The source term used in reactor safety analysis requires understanding the chemical speciation and transport behavior of fission and activation products under accident conditions. As a starting condition, the transport models will use the isotopic compositions determined through ORIGEN calculations and thermochemistry that describes the speciation of the fuel, the salt, activation products, and fission products. However, as changes in phase will be under nonequilibrium conditions, the source terms will also need models for the transport behavior of key compounds in the PHTS under various scenarios: normal operation with and without an off-gas system, maintenance, off-normal events, and severe reactor accidents. This document highlights those mechanistic behaviors for which models are needed. Simulations of reactor behavior require these models to be developed for MSRs, especially if not part of the suite used in describing light water reactor (LWR) behavior. The document concludes with recommendations how to develop models based on what is already known about reactor safety and fission product behavior.

Several types of MSRs are being considered for testing and commercialization, including those that have fuel salt and those that have ceramic fuel and circulating coolant salt. The ceramic fuel-coolant salt type reactors have similarities with high-temperature gas cooled reactors with salt being separated from the solid fuel during normal operation. Hence, this study focuses on the requirements for describing the source terms of salt-fueled reactors where the fuel is circulated through the PHTS and cladding does not contribute to the retention of fission products.

Fluoride-based salt reactors have been operated successfully. Data from the MSRE can provide information on several topics, from initial contamination to fission product loading. However, the MSRE was never meant to operate as more than an experimental apparatus. Calculations for reactor performance have been done on the MSBR, which was fully designed but never built and operated. The salt for the MSBR PHTS is a mixture of $\mathrm{LiF}-\mathrm{BeF}_{2}-\mathrm{ThF}_{4}-\mathrm{UF}_{4}(71.5 \%-16 \%-12 \%-0.5 \%)$.

Specifications for a chloride-based MSR are much more speculative because such a reactor has not operated. Several designs for chloride-based MSRs are available and include a combination of salts:

- Fast spectrum-MSR breeder fuel salts: $\mathrm{NaCl}-\mathrm{KCl}-\mathrm{PuCl}_{3}, \mathrm{PuCl}_{3}-\mathrm{NaCl}\left(40 \% \mathrm{PuCl}_{3}\right)$

- Coolant salts: $\mathrm{NaCl}-\mathrm{MgCl}_{2}, \mathrm{KCl}-\mathrm{MgCl}_{2}, \mathrm{LiCl}-\mathrm{KCl}-\mathrm{MgCl}_{2}, \mathrm{LiCl}-\mathrm{RbCl}, \mathrm{LiCl}-\mathrm{KCl}$

- Other diluents: $\mathrm{MgCl}_{2}, \mathrm{CaCl}_{2}, \mathrm{KCl}-\mathrm{SrCl}_{2}-\mathrm{RbCl}$

Safety analysis for MSRs is in the early phases. Source term modeling will inform and couple with the off-gas and monitoring activities, which will be developing the means to monitor fission products in situ and remediate the off gas during reactor operation. The objective is to show that no accidents challenge containment barriers and address the potential for multiple locations for radionuclides. 
The following studies are recommended in the near term:

- Thermodynamic scoping calculations for key areas of the PHTS need to be completed for representative fissile, fission, and activation products of interest (e.g., noble metals, cesium, strontium, iodine, tritium, rare earths) and corrosion products (e.g., chromium).

- Based on the thermodynamic calculations, the vapor pressures of important fission product species need to be measured. Key volatiles and their vapor pressures can be measured in a thermogravimetric apparatus coupled with a mass spectrometer. One such apparatus, the Netzsch Skimmer, will be installed at Oak Ridge National Laboratory in late CY 2018.

- In LWR safety analysis, many fission products can be grouped into classes, such as the noble metals, to simplify the safety analysis. Fission products of MSRs will be approached in a similar manner, but characteristics of typical behavior for each group need to be established. This activity will also identify outliers (i.e., fission products whose behavior deviates that of the group and thus affects the source term).

- Differences between the MSR source term definition and established LWR practice will be identified. This activity will show where model development is most needed.

- Literature that describes chemical transport in nonequilibrium conditions will be reviewed. For instance, in addition to temperature, phase change rate will depend on natural circulation and convective currents in the headspace as well as turbulence and flow rate in the salt. This information will inform model development.

- Experiments will be conducted to investigate the volatility of a nonradioactive fission product compound (e.g., iodine chloride) from a molten chloride salt under various headspace conditions (e.g., gas sparging rates). The work will support model development and validation for volatile species transport at the vapor-liquid interface.

- Existing reactor performance models for normal reactor operation will need to be extended to include off-gas performance and graphite interactions. This can be done for different simulation platforms, such as for TRANSFORM and MELCOR, and will allow a rigorous a cross-code comparison.

- The off-normal and accident scenarios proposed in this report are highly speculative. The fission product source term work package needs to coordinate with safety and licensing activities to identify scenarios for off-normal performance and the possible effects on the source term. These events could include the following:

- Maintenance outage

- Small leak in PHTS

- Design basis accidents

- Severe accident

- Waste form leakage

- The effect of radiolysis in the primary system and subsystems such as the off-gas scrubber system needs to be assessed. Physical and chemical processes could be modeled and experiments proposed as a result of the assessments.

- As with the reactor accident scenarios, the safeguards implications in MSRs listed earlier are speculative. A safeguards assessment can build on the source term evaluation and physicalchemical models describing fission product transport. 


\section{FUNDAMENTAL CHEMISTRY}

\section{Fundamental Chemistry}

Report: ORNL/SPR-2018/864

Multi-Physics Simulations for Molten Salt Reactor Evaluation: Chemistry Modeling and Database Development

To aid in design of MSRs, a framework integrating the complex interaction of reactor neutronics, thermal hydraulics, and chemistry is being developed within the DOE ART Program's MSR campaign. The challenges of integrating thermochemical and thermophysical behavior into multiphysics reactor simulations include the following:

- population of data needed for refinement of current models and development of new models through experimental measurements, first-principles calculations, and development of a machinelearning approach;

- thermochemical and thermophysical model development;

- further development of Thermochimica, an open-source efficient equilibrium solver used to link thermochemical models to the multiphysics code;

- a framework for integrating kinetic phenomena: nucleation, precipitation, mass/heat transport, and corrosion models; and

- a computational environment to efficiently utilize the data and models within a multiphysics modeling tool.

These challenges are being addressed through a collaboration among ORNL, ANL, the University of South Carolina, and the University of Ontario Institute of Technology. The effort resulted in the following conclusions:

- CALPHAD models will be used to represent thermochemistry and phase equilibria.

- DAT files will contain thermodynamic information.

- Thermochimica will link CALPHAD models to multiphysics code.

- Thermophysical property mathematical relations will be defined.

- $\quad$ Data needs will be identified.

- Measurements needed to fully develop both the thermophysical and thermochemical aspects of the Chemistry Database will be made.

A combined computational and experimental effort is under development to begin to fully develop the MSR Chemistry Database. It is a collaborative effort that leverages the strengths of each institution involved. Synergy is provided when capabilities and expertise overlap. A central feature of this collaborative effort is the Netzsch Skimmer, which has been purchased and will be installed to measure equilibrium vapor pressures for molten salt systems of interest to MSRs. 



\section{LICENSING}

\subsection{MAJOR ELEMENTS OF SAFETY AND LICENSING ROADMAP FOR MOLTEN SALT REACTORS}

ORNL prepared A Safety and Licensing Roadmap to Identify the Research and Development Gaps of Commercial Molten Salt Reactors, ORNL/TM-2018-944, to reflect their safety characteristics in a wellcoordinated licensing requirements approach. MSRs both inherently and through good design possess highly desirable safety attributes. Successful commercial deployment of MSRs is heavily dependent on a well-defined licensing program. The approach outlined is based on adapting the MSR licensing process to the current LWR-based NRC process that exists today, which has been the traditional approach used by new technologies such as the Pebble Bed Reactor licensing application, the Clinch River Breeder Reactor licensing application, and more recently the NuScale licensing application. NRC has recognized some of the unique passively safe aspects of advanced non-LWR reactors and has introduced an advanced reactor strategic plan to address the policy issues needed to accommodate advanced reactor concepts within the existing regulatory framework. Examples of some of these policy issues are the use of functional containment, the use of mechanistic source terms, and more reliance on performance-based and riskinformed regulatory processes, such as the Licensing Modernization Project, which emphasizes the use of risk-informed processes to select licensing basis events; safety categorization of structures, systems, and components (SSC); and well-defined defense-in-depth systems. Applying performance-based, riskinformed regulatory processes is, consequently, vital to substantially decreasing the cost, time, and uncertainty of commercial MSR reactor licensing while providing for the health and safety of the public and protecting the environment. This document is intended to provide a roadmap for the licensing and safety activities necessary to provide a path to commercialization.

Successful commercial deployment of MSRs should include DOE working closely with industry and the NRC to identify and resolve key licensing and regulatory issues for advanced reactor developers, future owner/operators, and other affected industry stakeholders. The application of unique DOE national laboratory resources, intense and focused stakeholder engagement, and impactful collaborations that establish key parts of the necessary regulatory pathway for all non-LWRs, including MSRs, will support the establishment of the necessary regulatory infrastructure to bring these advanced reactors to commercialization in an economic and timely manner. The goal of all activities summarized in this plan is the establishment of a licensing path for MSRs that is sufficiently well defined so that MSR developers, their sponsors, and interested owner/operators can move forward with increased regulatory clarity and reasonable assurance of timely, cost-efficient deployment.

The four primary constituents of the regulatory framework that must be established to significantly reduce regulatory uncertainty for MSRs address three basic issues, which are summarized below:

- Adequacy of the regulations

- Establish or update NRC policies as applicable to MSR topics.

- Develop adaptations and updates to NRC's existing LWR-based regulations and regulatory guidance.

- Technology-specific technical requirements for satisfying the regulations

- Define requirements based on testing and research and development (R\&D) (e.g., fuel performance, salt science, decay heat removal), including associated industry codes and standards. 
- Process for predictable and timely NRC review of a submitted license application

- Establish methods that encourage incremental and frequent NRC feedback on specific technology development issues and early design efforts (i.e., enable a "staged licensing review”).

The report references the NRC's current structure for LWR application reviews and notes the research areas for DOE to support MSR licensing. DOE national laboratories provide resources such as staff experienced in advanced reactor technologies, experimental facilities, and technical information useful to NRC and industry in addressing these issues. Regulatory development activities then utilize these resources to propose and support adaptations and changes to the existing LWR-based regulatory framework so that it can be applied to MSRs. Active and ongoing collaborations among the stakeholders, including the DOE-NRC interface, are vital to ensuring that priority R\&D is closely aligned with regulatory framework development so that MSR licensing and safety do not impede MSR deployment.

The number of possible salts and material combinations leads to a broad range of potential MSR concepts. However, for a basic representation, MSRs can be classified into the following groups:

- Salt-cooled reactors, in which a solid fuel undergoes fission and is cooled by a separate, nonfueled primary system salt; and

- Salt-fueled reactors, in which a flowing salt contains fissile material that fissions when in the core and flows throughout the primary system, thus serving as fuel and coolant.

Salt-cooled and salt-fueled MSR concepts have many common technological needs. Examples include affordable fabrication and construction methods, large-scale salt production, large-scale pumping and heat exchange, source-term definition and behavior characterization, and modeling and simulation tools to evaluate performance and safety to facilitate licensing.

Both salt-cooled and salt-fueled concepts can be fast, epithermal, or thermal spectrum reactors. However, salt-cooled concepts of current interest are mainly thermal spectrum concepts that use fluoride salts as the primary coolant. This class of reactors, known as fluoride salt-cooled high-temperature reactors (FHRs), has been the subject of much of the recent MSR research. Salt-fueled thermal spectrum reactors typically use fluoride salts with fixed moderating material within the core. Fast spectrum salt-fueled concepts can use fluoride or chloride salts and do not require in-core moderating material. Less recent research has been performed on salt-fueled MSRs.

\subsection{SUMMARY OF MAJOR FINDINGS FROM PROPOSED NUREG-1537 UPDATE}

An adaptation of NUREG-1537, Guidelines for Preparing and Reviewing Applications for the Licensing of Non-Power Reactors, was prepared to guide application preparation and review of generic, salt-fueled non-power reactors. The most significant safety and licensing change for MSR technology regards the references in NUREG-1537 to heterogeneous fuel elements consisting of rods, plates, or pins with fuel cladding acting as the initial fission product barrier. Reactor safety and, therefore, licensing requirements for solid-fueled reactors involves protecting the cladding, preventing the release of fission products, and transferring adequate heat through the cladding to limit the fuel centerline temperature. The initial fission product barrier in a liquid-fueled MSR is the fuel system boundary. MSR temperature increases are limited by the strong temperature reactivity coefficient. Integrity of the high-temperature, low-pressure fuel salt system boundary is a primary safety goal for an MSR. As a result, liquid-fueled MSRs become chemistry-based machines as opposed to mechanical-based machines. The MSR safety and licensing focus must shift primarily to the chemistry environment. Even in a performance-based regulatory structure, such as NUREG-1537 for nonpower reactors, this requires a different approach to be stated with new supporting analyses. 
Some delayed neutrons will be produced outside the active reactor core because of the nature of the flowing fuel solution and its movement out of the active reactor core. Any sudden reduction in flow, such as a transition from forced flow to natural circulation flow, will result in a subsequent reactivity addition. Therefore, the ability to control the core during normal operation and core flow changes must be considered in safety and licensing documentation for liquid-fueled MSRs.

The typical means to control reactivity in an LWR is using neutron-adsorbing control rods. However, there are many more options for controlling reactivity in an MSR. Reactivity can be controlled in MSR designs through fuel displacement, neutron absorption, neutron reflection, neutron spectral adjustment, or a combination of these methods. MSR control elements can be solids, liquids, or gases to dispel fuel salt from the core and can be passively or actively positioned.

In addition, MSRs operate with minimal excess reactivity. Therefore, to operate for any length of time, provisions for adding fuel during operation are necessary. Likewise, provisions are made for salt makeup in the various MSR salt loops. This requires safety and licensing analysis documentation not required for LWRs.

Gaseous, soluble, and insoluble fission products are generated within the fuel salt as an MSR is operated. Gaseous fission products accumulate within the vessel or within a cover gas at a free surface boundary. Safety and licensing discussion of a gas management system must be included to describe the design of the system for removing fission product gases from the core and cover gas of an MSR. Decay heat removal must be considered for the gas management system and other segmented portions of the reactor that contain fuel salt.

Heat is transferred from MSR fuel salt through a heat exchanger to cooling systems that do not include fuel. Therefore, the former heterogeneous-fuel-based primary coolant system no longer exists with the same function as provided for LWR fuel. Therefore, the safety and licensing analysis and documentation of the heat transfer in an MSR is more complex than for heterogeneous-fueled reactors.

Safety and licensing documentation for auxiliary systems should include homogeneous MSR fuel handling and storage of the special nuclear material (SNM) used for reactor fuel (both new and irradiated), including systems (tanks, valves, pumps, instrumentation, controls), processes (chemical blending, SNM transfers, waste storage, preparation for shipment), criticality monitoring, vaults, shielding, and contamination control. The documentation should address the form of the fuel during storage and handling. For facilities designed to fabricate fuel on site, the discussion should include a description of the form in which the fissile material is received, how and where it is stored before use, and how it is blended into a useable liquid fuel, including criticality control measures and monitoring.

The use of liquid fuel adds numerous new issues pertaining to quantification of by-products, sources, and SNM that differ from the use of heterogeneous fuel elements. Licensing documentation should indicate that an effective means is defined for limiting the SNM at the reactor site to establish an envelope used for safety and security analyses. Consideration should be given to the fact that fuel isotope quantities in the fuel salt will change during normal operation, as ${ }^{235} \mathrm{U}$ is depleted, as ${ }^{238} \mathrm{U}$ converts to ${ }^{239} \mathrm{Pu}$, or as ${ }^{233} \mathrm{U}$ converts to ${ }^{232} \mathrm{Th}$.

Waste management is significantly different for an MSR when compared to an LWR. In an MSR, fission products are released to the molten salt fuel solution and are contained by the fuel salt boundary. In an LWR, fission products are released to the fuel rod gap space and are contained by the fuel cladding. MSR gaseous fission products migrate directly to the gas space in the top of the vessel and enter the gas management system to be processed within the fission product barrier. The fission gas may require holdup for decay or further treatment before being recycled as cover gas, released to the environment, or disposed of as waste. If applicable, residue from mechanical cleanup or polishing of soluble fission products will require treatment as radioactive waste. 
Some nonpower reactor licenses do not allow the "separation of isotopes" or the "separation of byproduct materials" to enforce regulations dealing with the separation of plutonium or the enrichment of ${ }^{233} \mathrm{U}$ or ${ }^{235} \mathrm{U}$ to produce SNM. In the strictest sense, that could be interpreted as not allowing the removal of wastes from MSR liquid-fueled cores. In a liquid-fueled MSR, fission gases do this inherently by simply separating or rising from the fuel salt, such as in the fuel salt circulating pump boil or a cover gas space. Other undesired fission products are removed from the liquid fuel by waste treatment processes with no intention of producing SNM. Therefore, waste treatment processes must be clearly defined in the safety and licensing documentation using unambiguous terms. The waste management program should be described in a manner showing that processes effectively remove undesired materials from the liquid fuel without providing a means for fissile material separation and collection in the process. 


\section{SAFEGUARDS}

Safeguards to prevent tampering or loss of inventory require unique consideration for MSRs. A listing of recommended activities related to safeguards was created as a suggested starting point for an activity that will produce a complete needs assessment of MSR reactor systems, secondary systems that may experience dose and activation, and on-site and off-site salt processing systems. Because of the importance of MSR chemistry on reactor operation, it is likely that the PHTS and secondary processes will be instrumented with detectors for various isotope concentrations in salt inventories. Monitoring requirements for normal reactor operation can play an important safeguards function. Such requirements will need to be assessed in the context of safeguards because small amounts of removal might not be detectable in a high radiological background.

The highly radioactive nature of the salt will make tampering difficult and dangerous. However, there may be less deterrence in the case of consumables, such as off-gas components or replacement graphite structures. Tritium may be of value, particularly if it is loaded onto absorbents and removed. Thus, waste streams may be the more important consideration for safeguards. Penetration of the PHTS or tampering with the reactor loop itself is considered unlikely because of the high-radiation fields unless a complete reactor shutdown was the goal. However, auxiliary components, such as consumable scrubbers or getters, could be a target for unauthorized processing.

Salt processing may take place some distance from the reactor itself to establish a physical distance between the reactor and the chemical plant. Reactor operations and safety issues will likely benefit from proximity to hydrogen, chlorine, or other large industrial gas systems. However, whether online or offline, the transportation of the salt may present safeguards issues that will need to be addressed.

MSRs may be run in several different configurations. In some cases, the MSR will be loaded with fuel and run continuously until the actinide fuel is spent and the reactor is permanently shut down (for 7 or 8 years). Other configurations suggest loading the reactor with fertile material and a small amount of fissile material at start-up. In either case, the fuel value of the nuclear waste will be minimal at the end of the reactor lifetime. Spent nuclear waste could be stored on site until it had decayed to an activity level that would allow it to be transported to a permanent repository. With regard to vulnerability, the transportation of the fuel and the permanent disposal may pose the greater risk for interception. Although the actinide inventory may be minimal, radioactive fission products could be captured from the salt by simple dissolution because the salt is not contained within a ceramic envelope. 



\section{WASTE FORM EVALUATION}

PNNL Report: NTRD-MSR-2018-000379, PNNL-27723

Identification of Potential Waste Processing and Waste Form Options for Molten Salt Reactors

Several moderately to highly mature processes and technologies exist that could be implemented to manage MSR off-gas streams, including those for noble gases (e.g., $\mathrm{Xe}, \mathrm{Kr}$ ), reactive gases (e.g., halides), hydrogen (e.g., ${ }^{3} \mathrm{H} 2(\mathrm{~g}), 3 \mathrm{HF}$ ), particulates, and aerosols. Off-gas capture and immobilization have been studied for decades, and thus a wealth of knowledge exists in the literature. Advanced sorbents with high technical maturity exist, including metal-exchanged zeolites (e.g., AgZ, AgX), Ago-functionalized silica aerogels, activated carbon, and metal-organic frameworks. Molten hydroxide or aqueous hydroxide scrubbers could also be used to clean off-gas streams.

For the salt-based streams, recent work has been done to develop and test waste forms for chloride-based pyrochemical processing salt wastes, and it is likely that many of the chloride-based MSR options could benefit from this research. Some could also be applied to fluoride-based MSR salt wastes. Several waste forms have been identified, including glass-bonded ceramics (e.g., sodalite, apatite) and glasses (e.g., lead tellurite). Additional, less-mature technologies are currently under investigation that show promise for dehalogenation (i.e., I and $\mathrm{Cl}$ removal) of halide salt wastes that could be used for ${ }^{37} \mathrm{Cl}$ recycling and for improving waste loading in the final waste forms. These options include reactions between the salts and phosphate precursors (i.e., phosphate glass waste form) or ultrastable H-Y zeolite (i.e., glass-bonded zeolite or glassy waste forms).

It is likely that graphite will be one of the largest waste fraction streams (if not the largest waste fraction stream) coming from thermal-spectrum MSRs. Thus, to limit the volume of the graphite waste fraction, recycling the graphite is an attractive path forward and has been demonstrated (albeit on simulants and on a small scale) using different techniques.

Processing the primary system metal into a waste form is likely as simple as reducing the sizes of the components and then either melting or compacting them into a monolithic form for storage and disposal. However, some complications of this approach could arise, considering the potential volatility of fission products entrained in the metallic reactor components during the process of immobilization (e.g., hightemperature melting). Although that issue does not eliminate high-temperature melting as a possible immobilization approach, it does introduce added requirements, such as methods to capture potential volatiles evolving during the melting process.

The wastes that result from decontamination and decommissioning as well as operating wastes can likely be dealt with through size reduction, packaging, and processing as low-level waste or greater-than-class-C wastes.

The following are the primary areas in which more work is needed for the effective treatment and storage of effluents and wastes generated during the operation of a generic MSR and processing of the waste that it generates:

- Determine specific waste compositions, isotope concentrations, and mass estimates. Develop a reference mass balance for MSR effluents for each of the four baseline cases studied. This analysis should include the waste streams from anticipated processing of reactor materials, online and during decommissioning. Perform a systems analysis study of the optimal treatment and disposal options for those wastes, as was done for electrochemical salt wastes.

- Develop functional requirements for disposal of MSR wastes. Develop initial functional and operational requirements for the disposal of salt, carbon, products of separations, and other MSR wastes. Compare these functional and operational requirements with the current generic 
repository design concepts of the DOE Office of Nuclear Energy (NE) Spent Fuel and Waste Disposition Program.

- Initiate off-gas treatment technology testing. Evaluate and test getters and scrub systems for noble gases (e.g., $\mathrm{Xe}, \mathrm{Kr}$ ), reactive gases (e.g., halides), hydrogen (e.g., ${ }_{3} \mathrm{H}_{2}(\mathrm{~g}), 3 \mathrm{HF}$ ), particulates, and aerosols for reactor operation.

- Investigate waste form options for salt streams and separated salt streams. Begin scoping tests (e.g., waste loading, performance testing, storage effects such as radiation and heat) for high-halide salt containing high-level waste streams, starting with the most promising options (e.g., glass-bonded sodalite, glass-bonded apatite, cermets, phosphate glass).

- Treat and/or recycle contaminated carbon-based materials (i.e., graphite). Develop simulants for contaminated graphite and perform scoping tests for treatment/recycling options (these may require simulated reactor irradiations). Evaluate treatment options and select options to evaluate (e.g., CARBOWASTE Program).

- Investigate the radiolysis and chemical kinetics of interactions between waste isotopes and structural materials. The kinetics are likely not to be homogeneous, and so the microstructures and grain boundaries of materials will have to be considered. The salt itself is likely to phasesegregate when cooled, which will add complexity to the model. Liberation of gases, some of them corrosive, must be considered in choosing options for storage and disposal.

- Investigate methods for ${ }^{7} \mathbf{L i}$ and/or ${ }^{37} \mathbf{C l}$ recovery. In an attempt to moderate the financial liabilities of MSR concepts, it will likely be beneficial to recover ${ }^{7} \mathrm{Li}$ from Li-containing salts and ${ }^{37} \mathrm{Cl}$ from Cl-containing salts. To support this effort, recovery/recycling concepts should be evaluated. 


\section{MODELING AND SIMULATION}

Report: NTRD-MSR-2018-000367

Molten Salt Reactor Campaign Modeling and Simulation Program Plan

The modeling and simulation activities within the MSR Campaign facilitate the development and application of analysis tools for the design and licensing of MSRs. This included an assessment of the modeling and simulation functional needs for MSRs for licensing and design. The assessment is generated using a licensing-focused approach considering the modeling and simulation components that contribute to an MSR safety analysis report. These functional needs are prioritized by identifying the relationships between functional needs and using a blind weighting scheme to identify the most critical components to build a licensing case. In addition, functional need inputs are ranked to reveal those that feed the most modeling and simulation components. The modeling and simulation objectives of the MSR Program are drawn directly from the findings of this prioritization effort, with some additional expert judgement.

The identified modeling and simulation needs fall into three focus areas: (1) source term definition, material accountancy, and radiological consequences; (2) safety analysis; and (3) steady-state neutronics and thermal hydraulics. Five near-term goals were identified among these focus areas that add value and draw on current DOE capabilities:

- deploying a systems and safeguards analysis computational tool,

- defining source term analysis and interfacing with the NRC on accident progression analysis,

- developing point designs for liquid-fueled thermal-spectrum and fast-spectrum MSRs,

- building safety analysis specifications and reference solutions for MSRE transients, and

- interfacing with the thermophysical and thermodynamic salt chemistry databases.

The intent is to accomplish these goals over the course of 4 years, beginning FY 2019, provided that resources are adequate and changes to these objectives are not significant. 



\section{COMPATIBILITY STUDIES OF NON-METAL MATERIALS}

\subsection{STATIC CAPSULE EXPOSURES OF SALTS AND STRUCTURAL MATERIALS}

Report: Compatibility Studies of Cladding Candidates and Advanced Nickel Superalloys in Molten KCl$\mathrm{MgCl}_{2}$

Exposure of $26 \mathrm{NaCl}-\mathrm{MgCl}_{2}$ capsules containing commercial alloys, ORNL-developed nickel superalloys, and cladding candidate materials were initiated. Experiments were run at $700^{\circ} \mathrm{C}$ for $500 \mathrm{~h}$. Characterization is currently in progress and results are anticipated in early FY19. The results will be used for down-selection of a small number of alloys for further testing at varied temperatures and salt chemistries.

Exposure of two graphite samples and one SiC sample to FLiBe were completed. This activity exercised the abilities at ORNL to handle beryllium-containing salts within laboratory regulations, and the procedures developed should enable more efficient future work. Graphite samples have been sent to an outside laboratory to characterize penetration of the salt into the graphite.

A design for a new crucible-style testing method with an antechamber has been completed. It will allow infiltration studies of graphite samples at pressures of up to 10 bar. Also, the associated sample holder allows for the evaluation of up to six samples in the same test. Components have been ordered, and machining of insert crucible and sample holder will be completed soon.

A two-glovebox assembly for handling of samples exposed to FLiBe salt is under construction. One box (left side) will have an argon (or nitrogen) atmosphere, which can be recirculated through a highefficiency particulate air (HEPA) filter. The connecting box (right side) will have room air that has passed through a HEPA filter. Capsules containing the FLiBe salt will be put into the transfer chamber on the left end and then moved into the left glovebox. The capsules will be opened in that box and the opened capsules containing the FLiBe salt will be stored in sealed bottles. The samples will be removed from the capsule and then moved to the right box, where an ultrasonic water bath will be used to dissolve any salt on the samples. Once cleaned, the samples will be checked for Be contamination, and if clean, they will be removed from the box through the transfer chamber on the right side. A microscope in the right box will be available for inspection of samples that cannot be adequately cleaned or for inspection of samples before cleaning.

The following activities related to capsule corrosion studies were undertaken:

- Surveyed the literature regarding compatibility of graphite with molten salts. Information is being reviewed and compiled to publish a report in FY 2019.

- Categorized the multiple graphite grades available to identify candidate materials based on available information and properties.

- Acquired blocks of graphite in grades of interest for use in MSRs and machined samples for compatibility studies.

- Demonstrated the suitability of the current capsule design (molybdenum) for compatibility studies of graphite and molten salts, using FLiBe.

- Exposed two samples of fine-grain graphite (grade 2114) to FLiBe, one for $500 \mathrm{~h}$ and one for $1,400 \mathrm{~h}$.

- Opened the capsules and examined the graphite samples using a small handheld microscope. Images were collected. Some preliminary findings include the following:

- The graphite sample surfaces were relatively clean of salt. 
- No major visible salt concentrations were found on the graphite surfaces after they were removed from capsule.

- Small drops of salt (very small bright spots) observed on the surfaces of the graphite specimens appear spherical, indicating low wetting and limited adhesion to surface.

- A graphite sample exposed to FLiBe for $500 \mathrm{~h}$ has been sent to an outside laboratory for scanning electron microscopy (SEM), energy dispersive X-ray spectroscopy (EDS), quantitative elemental analysis (glow-discharge mass spectrometry) and depth profiling for $\mathrm{Li}, \mathrm{Be}$, and $\mathrm{F}$ to determine depth and nature of salt penetration.

- Completed the design of a high-pressure capsule for infiltration studies using multiple samples.

- Established contact with several MSR reactor vendors to discuss their needs related to graphite properties and compatibility with molten salt. Their feedback will be incorporated into our workplan.

- A handheld, low magnification optical microscope with a Wi-Fi connection was procured for visual inspection of the samples removed from capsules. A microscope with optical and metallographic capabilities and higher magnification with polarized light will be purchased to go into the glove box.

\begin{tabular}{|c|c|c|c|c|c|c|c|c|c|c|c|c|}
\hline & & $\begin{array}{c}\text { Grain } \\
\text { size [um] }\end{array}$ & $\begin{array}{l}\text { Pore size } \\
\text { (um) }\end{array}$ & Density & Billetsize & Purity & Cost & $\begin{array}{l}\text { County of } \\
\text { origin }\end{array}$ & $\begin{array}{l}\text { Iradia- } \\
\text { tion data }\end{array}$ & $\begin{array}{l}\text { Inadiatio } \\
\text { n lifetime }\end{array}$ & Isotropic & $\begin{array}{l}\text { Sill } \\
\text { manufac- } \\
\text { tured }\end{array}$ \\
\hline \multirow{7}{*}{ 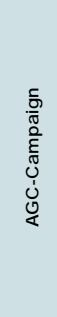 } & $\mathrm{H}-451$ & Medium & $5-100$ & 1.71 & & & & SGLUSA & Low dose & & Extruded & \\
\hline & NBG-17 & Medium & $8-30$ & 1.86 & Large & $<5 \mathrm{ppm}$ & $\$$ & $\begin{array}{c}\text { SGL(Germany/ } \\
\text { France) }\end{array}$ & Low dose & & Vibro-molded & \\
\hline & NBG-18 & Medium & $5-50$ & 1.87 & Large & $<5 \mathrm{ppm}$ & $\$$ & $\begin{array}{c}\text { SGL(Gemany/ } \\
\text { France) }\end{array}$ & Low dose & & Vibro-molded & \\
\hline & PCEA & Medium & 5-100 & 1.79 & Large & $<5 \mathrm{ppm}$ & $\$$ & Graftech (USA) & Low dose & & Extruded & \\
\hline & IG-110 & Fine $<100$ & $<1$ & 1.76 & Large & $<5 \mathrm{ppm}$ & $\$$ & Toyo (Japan) & Low dose & & Iso-molded & \\
\hline & $\begin{array}{l}\text { IG-430 } \\
\text { (dropped) }\end{array}$ & Fine $<100$ & $<1$ & 1.80 & Large & $<5 \mathrm{ppm}$ & $\$$ & Toyo(Japan) & Low dose & & Iso-molded & \\
\hline & $\begin{array}{l}2114 \\
\text { (added) }\end{array}$ & Fine $<100$ & & & Large & $<5 \mathrm{ppm}$ & $\$$ & $\begin{array}{c}\text { Mersen } \\
\text { (France-USA) }\end{array}$ & Low dose & & & \\
\hline MSRE & CGB & Medium & & 1.86 & Small & & & $\begin{array}{l}\text { Union Carbide } \\
\text { (USA) }\end{array}$ & & & Extruded & \\
\hline \multirow{6}{*}{ 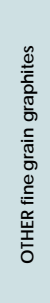 } & $\begin{array}{l}\text { POCO- } \\
\text { ZXF-5Q }\end{array}$ & $\begin{array}{l}\text { Microfine } \\
<2\end{array}$ & 0.3 & 1.78 & Small & $<5 \mathrm{ppm}$ & $\$ \$$ & USA & Low dose & & Iso-pressing & \\
\hline & $\begin{array}{l}\text { POCO- } \\
\text { AXF-50 }\end{array}$ & $\begin{array}{l}\text { Ultra fine } \\
<10\end{array}$ & 0.8 & 1.78 & Small & $<5 \mathrm{ppm}$ & $\$ \$$ & USA & Low dose & & Iso-pressing & \\
\hline & POCO-TM & $\begin{array}{l}\text { Ultrafine } \\
<10\end{array}$ & 1.5 & 1.82 & Small & $<5 \mathrm{ppm}$ & $\$ \$$ & USA & Few data & & Iso-pressing & \\
\hline & G347A & $\begin{array}{c}\text { Ultra fine } \\
<10\end{array}$ & & 1.85 & Large & $<5 \mathrm{ppm}$ & & Tokai(Japan) & High dose & & Iso-pressing & \\
\hline & IGS743NH & $\begin{array}{l}\text { Superfine } \\
<50\end{array}$ & & 1.80 & Large & & & $\begin{array}{l}\text { Nippon } \\
\text { (Japan) }\end{array}$ & Low dose & & Iso-molded & \\
\hline & пU10 & Fine $<100$ & & & & & & $\begin{array}{l}\text { Ibiden } \\
\text { (Japan?) }\end{array}$ & & & & \\
\hline
\end{tabular}

Figure 1. List of various graphite grades and their characteristics.

\subsubsection{SiC Composite Research}

The $\mathrm{SiC}$ materials group participated in and completed several activities within the MSR Campaign during FY 2018. Activities included the preparation of specimen materials for the first FLiBe exposure tests, preparation for lithium fluoride-sodium fluoride-potassium fluoride (FLiNaK) salt exposure tests, and the completion of a technology gap analysis for SiC/SiC composites for MSR applications.

\section{FLiBe Exposure Study (Activity Lead: J. Keiser)}

A nonmetal molten salt capsule exposure plan was developed. According to the plan, several grades of $\mathrm{SiC}$ materials have been prepared for molten salt corrosion tests. The materials include a high-purity SiC monolith with different microstructures (such as grain structure and type of processing defects), produced 
by chemical vapor deposition (CVD), SiC-fiber-reinforced composites with different fiber materials produced by chemical vapor infiltration, and a representative pyrocarbon interphase in $\mathrm{SiC}$ composites as shown in Figure 2.

(a)

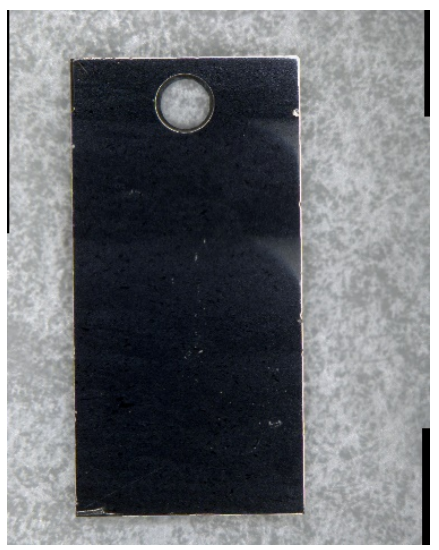

(b)

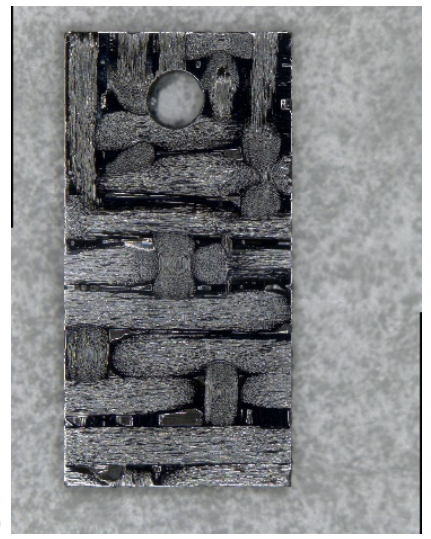

Figure 2. Images of the specimens that have been prepared: (a) SiC monolith specimen with a smooth surface and (b) SiC composite specimen.

The first SiC specimen, of CVD SiC material from Dow Chemical, was exposed for $500 \mathrm{~h}$ to FLiBe at $700^{\circ} \mathrm{C}$. The capsule was opened on July 27,2018 , and the specimen was removed. Images were captured with a low-magnification hand-held optical microscope. The specimen was prepared with polished and unpolished surfaces, shown in Figure 3.

(a)
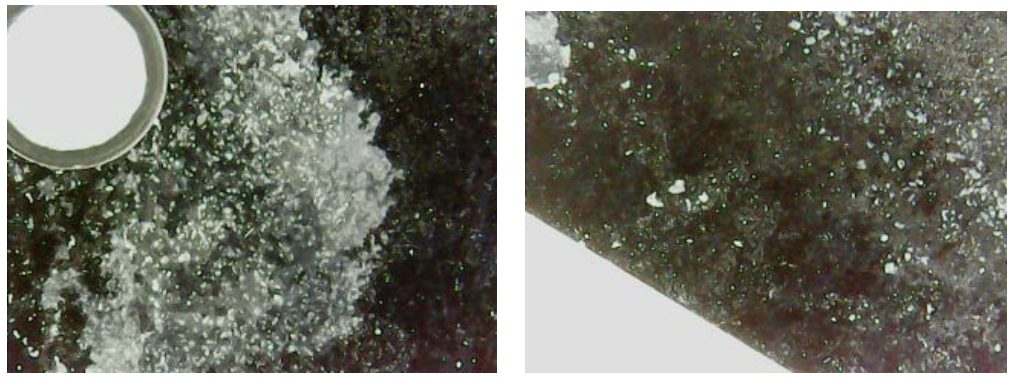

(b)
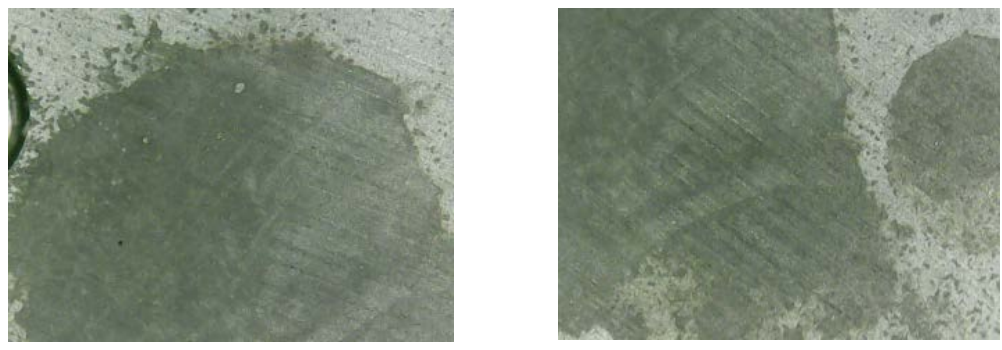

Figure 3. Images of the exposed SiC CVD specimen (a) polished shiny surface and (b) the unpolished dull surface.

Nonuniform "residue" areas of dark and light were visible on both sides. The specimen shape, edges, and attachment hole appeared to be intact. The next steps are to clean the specimen according to established in-house procedures. The Be contamination will be determined before the specimen will be characterized with various characterization techniques like cross-sectional SEM and line-scanning EDS and x-ray photoelectron spectroscopy elemental analysis. 
The next set of specimens have been prepared (Table 1). Part of basic microstructural characterizations of the specimens prior to corrosion tests have been conducted. The results of the characterizations will be useful to understanding the differences in corrosion resistance among those materials.

Table 1. Specimen matrix for FLiBe exposure tests.

\begin{tabular}{|l|l|l|l|l|l|l|}
\hline \multicolumn{1}{|c|}{ Material } & \multicolumn{1}{|c|}{$\begin{array}{c}\text { Material } \\
\text { ID }\end{array}$} & \# & $\begin{array}{c}\text { Length, } \\
\mathbf{m m}\end{array}$ & $\begin{array}{c}\text { Width, } \\
\mathbf{m m}\end{array}$ & $\begin{array}{c}\text { Thickness, } \\
\mathbf{m m}\end{array}$ & \multicolumn{1}{|c|}{ Polish } \\
\hline Dow Chemical CVD SiC & RH & 1 & 12.71 & 6.35 & 1.75 & One side \\
\hline RH annealed at $1900^{\circ} \mathrm{C}$ for $1 \mathrm{~h}$ under $\mathrm{Ar}$ & RH1900 & 1 & 12.8 & 6.36 & 1.72 & One side \\
\hline High-resistivity grade CoorsTek CVD SiC & HR-CT & 1 & 12.81 & 6.39 & 1.87 & One side \\
\hline Low-resistivity grade CoorsTek CVD SiC & LR-CT & 1 & 12.83 & 6.37 & 1.7 & One side \\
\hline HNS CVI SiC/SiC used for SCF rabbit & HNS-SCF & 1 & 12.79 & 6.35 & 0.95 & One side \\
\hline HNS CVI SiC/SiC used for SCF rabbit & HNS-SCF & 2 & 12.81 & 6.38 & 0.94 & One side \\
\hline SA3 CVI SiC/SiC used for SCF rabbit & SA3-SCF & 1 & 12.79 & 6.39 & 1.9 & One side \\
\hline SA3 CVI SiC/SiC used for SCF rabbit & SA3-SCF & 2 & 12.83 & 6.39 & 1.89 & One side \\
\hline Ibiden, PyC coated graphite plate & GC & 1 & 13.08 & 6.11 & 2.08 & None \\
\hline
\end{tabular}

These specimens will be characterized and then encapsulated during the last weeks of FY 2018 and will be available for inspection and evaluation during FY 2019.

\section{FLiNaK Exposure Study (Activity lead: S. Raiman)}

For the FLiNaK exposure study, an SiC materials test matrix was prepared. Similar to the FLiBe exposure study, corrosion coupons will be prepared that will be sealed in capsules following established in-house procedures similar to the testing of other materials such as metals. The plan is to expose, as a minimum, the materials listed in Table 1 , for a period of $500 \mathrm{~h}$ at a temperature of $700^{\circ} \mathrm{C}$.

Before exposure, the coupons will be prepared so that a baseline of the impurity level can be established. This is required for the specimen materials and the salt. The pre-exposure plan includes sonication or drying of test materials, elemental analysis of FLiNaK, surface elemental analysis of SiC coupons by diffraction, imaging and cross-sectional morphology, and mass measurements.

The post-exposure plan is to characterize the $\mathrm{SiC}$ coupon by weight change, corrosion depth, surface elemental analysis, and surface morphology.

\section{SiC/SiC composites technology gap for Molten Salt Reactors (Activity lead: W. Geringer)}

Report: ORNL/TM-2018/842

SiC/SiC Composites Technology Gap Analysis for Molten Salt Reactors

During FY 2018 a study was conducted to evaluate the SiC/SiC composites technology gap for MSRs.

The focus was primarily on solid fuel FHRs with FLiBe and FLiNaK as coolants, but gaps associated with liquid-fueled molten salt reactor (LFMSR) technologies were also investigated.

The report addressed gaps identified in the design methodology, fabrication constraints, physical and mechanical properties and chemical component interactions (corrosion) with SiC composite materials. It was a level 3 milestone report that was submitted in June 2018.

The purpose of the report is to identify the $\mathrm{R} \& \mathrm{D}$ gaps toward potential applications of $\mathrm{SiC} / \mathrm{SiC}$ components for Generation IV MSRs. 
There are several different MSR concepts, and they can be generally grouped into two classes: those with solid fuel and those with liquid fuel. The FHR, with solid fuel and molten salt coolant, and the LFMSR, a reactor wherein the fuel is dissolved into the molten salt, are the example concepts in these two classes, respectively. The primary candidate coolant for FHRs is a molten fluoride salt; LFMSR assumes the use of either fluoride and chloride salt mixtures. As a Generation IV reactor concept, MSRs shall demonstrate sustainability (mainly waste manageability), proliferation-resistant secure nuclear systems, competitive cost of energy, and safety and reliability (including acceptable performance of key materials for licensing).

The FHR concept is considered technologically more mature than other MSR concepts. The FHRs typically have a thermal neutron spectrum while other MSRs have been designed with epithermal or fast neutron spectra. Core outlet temperatures are in general below $750^{\circ} \mathrm{C}$ with pressures near atmospheric conditions. The FHRs feature high-temperature solid fuels, passive safety features such as auxiliary cooling systems like in sodium fast reactors, intermediate heat exchangers, and salt freeze tanks.

$\mathrm{SiC} / \mathrm{SiC}$ composites are particularly suitable for certain components in FHR systems because they have outstanding high-temperature capability and tolerance against neutron irradiation. Moreover, the MSRs in general will greatly benefit from the use of $\mathrm{SiC} / \mathrm{SiC}$ composites for components that need to withstand harsh operating environments combining some, or all, of high temperature, high neutron flux, high lifetime neutron fluence, and direct contact with molten salt, regardless of reactor concepts or designs. The materials and application technologies surrounding the $\mathrm{SiC} / \mathrm{SiC}$ composites are rapidly advancing as the materials are finding niche yet growing applications mainly outside the field of nuclear energy. However, significant $\mathrm{R} \& \mathrm{D}$ is needed before the $\mathrm{SiC} / \mathrm{SiC}$ composite materials and their application technology become ready for qualification of a design employing the components made of these materials.

The purpose of this study is to identify the remaining technology gaps for $\mathrm{SiC} / \mathrm{SiC}$ composite materials and to evaluate the material readiness with regard to MSRs on aspects concerning the maturity of design methods and rules, the materials and manufacturing techniques with focus on limitations regarding scalability and component sizes, material performance assessing mechanical and thermal property data, and the chemical interactions and compatibility. 



\section{REACTOR TECHNOLOGY DEVELOPMENT}

\subsection{INSTRUMENTATION AND CONTROL}

Report: ORNL/TM-2018-868

Instrumentation Framework for Molten Salt Reactors

This report supports the DOE NE MSR campaign through

- describing instrumentation's role and performance requirements throughout an MSR's lifecycle;

- providing a structured MSR instrumentation technology and state-of-the-art documentation; and

- identifying MSR instrumentation technology gaps and recommending research, development, and deployment to close the identified gaps.

This report describes the instrumentation that is anticipated to be employed to operate, maintain, inspect, refuel, construct, monitor, and eventually decommission future MSRs. The report includes a topologybased description of the instrumentation anticipated for each major plant area/function and provides a functional description of the anticipated measurement requirements throughout an MSR lifecycle. The nonoperational phases of the plant (e.g., maintenance and construction) and additional plant systems (e.g., waste handling, safeguards monitoring) are addresses as well.

MSRs are thermally based nuclear power plants (NPPs); as such, a significant amount of information can be obtained from prior thermal power plants and existing nuclear facilities. In fact, much of an MSR's process instrumentation will be identical to that employed in other high-temperature systems, as most process instruments do not directly touch the process fluid. However, simply overlaying conventional LWR instrumentation performance requirements onto MSRs is inappropriate because different reactor classes rely upon substantially different physical processes. The extensive historic MSR development program also provides a substantial amount of information on MSR test reactor instrumentation. However, due to the passing of five decades and the present emphasis on commercial deployment, the instrumentation for future MSRs will have considerable differences from the instrumentation in predecessor facilities.

All MSRs will be both passively safe and resilient against disturbances. Their advantageous characteristics will significantly influence the performance requirements of much of the instrumentation and controls (I\&C). For example, they will avoid the need for high-speed, safety-grade process monitoring due to the lack of rapidly progressing accidents. The need for automated intrusion monitoring to facilitate use of local law-enforcement personnel for plant security (enabled by the lack of accessible vital areas) will increase, and requirements to inspect/monitor passive safety features will need to be added to ensure that the safety features continue to be able to perform their functions.

The lower safety significance of individual MSR plant components will substantially decrease in-service inspection requirements. For example, the instrumentation required to assess flaws in the pressure retaining structures of LWRs will not be necessary in MSRs due to their independent, multilayered containment structures.

The liquid nature of an MSR's fuel while in service significantly alters the design and performance requirements of the plant's I\&C. Due to the fissile material's mobility and lack of confinement within cladding, the approach to fissile inventory tracking will be substantially different from the tracking that is used for solid-fueled reactors. Also, although the fission process changes the composition of the fuel in both liquid- and solid-fueled reactors over time, liquid-fueled reactors distinctively afford the possibility of gradually, purposefully altering the fuel composition over time. This is done to decrease corrosiveness, improve heat transfer properties, or remove neutron absorbers. Therefore, instrumentation will be needed to measure the evolving fuel salt composition and to subsequently control the salt chemistry. Moreover, 
the fuel salt composition can serve as a process history monitor. The fuel composition provides a confirmatory indication of average power level to calibrate or confirm the heat balance and/or reactor physics models, while the quantity of dissolved constituent elements from the container alloy provides evidence of corrosion progression. Therefore, components and instrumentation that provide access to the fuel salt will be a distinguishing aspect of MSR instrumentation. Because there will be a substantial amount of radioactivity outside the MSR's core, both radionuclide and fissile material tracking instrumentation will be required to demonstrate that the materials remain within their intended boundaries.

Because economically competitive energy generation is the overall objective for MSR development, this framework emphasizes the economic aspects of instrumentation technology. Enabling staff reduction through automation is a key framework element in achieving that goal because staffing costs at NPPs are a significant component of the overall power cost. Automation of in-containment activities is also especially important at MSRs due to their high local dose rates. MSRs lack the shielding inherently provided by the water coolant and thick reactor components of LWRs. Most modern MSR designs employ interior vessel shielding, which substantially reduces the in-containment dose rates. The very high local radiation level effectively prevents employing solid-state electronics within an MSR's biological shielding; long-handled tooling must be used for in-shielding manipulations. Simplifying the required set of measurements is also a key principle for this framework. For example, the heat balance for a pressurized water reactor is typically performed on the secondary side of the primary heat exchanger, providing the required information with higher reliability and lower cost. The recommended instrumentation development set only includes instruments for those measurements judged necessary to enable reliable plant operation as opposed to supporting scientific discovery.

The low fuel salt pressure also substantially alters the design and performance requirements for the plant I\&C. When compared with the mass of LWR components, the lower mass of components containing fuel salt and the lack of containment pressurization accident sequences significantly decrease the cost and difficulty of replacing system components. Consequently, all MSR components, including the reactor vessel, are intended for periodic replacement. The highly automated maintenance systems used to perform the replacements and the component health-monitoring instrumentation must be substantially more advanced than those in prior NPPs. Moreover, wiring and process sampling lines can easily be passed through a low-pressure boundary, so MSRs can more easily interconnect with advanced signal-processing electronics located outside their containment and shielding layers. The additional cabling and improved monitoring capabilities will facilitate using more advanced signal processing online, such as power signature analysis on pumps and valves and neutron noise monitoring on flux-monitoring systems. These features should provide increased confidence in the useful lives of components and should assist in avoiding unplanned shutdowns.

MSR designers can learn from decades of issues that have affected previous LWR deployments. One key lesson learned from decades of LWR deployments is that it is difficult to assess the health of large concrete structures without embedded sensors. Another lesson learned is that replacing safety-grade cabling within containment is difficult and expensive, largely due to the required fire protection and penetrations through containment. Modern MSRs will use much less safety-grade cabling than their predecessors because they employ much less safety-significant instrumentation and equipment. Furthermore, higher dose rates within MSR shielding will require that MSRs be equipped with metal and ceramic power cabling, which is expected to have a lifetime exceeding those of the plant structures.

Instrumentation-specific elements of the MSR supply chain are included in the framework. Any MSR vendor must have an adequate component supply chain. Dedicated MSR instrumentation is not generally available, so general-purpose and stand-off instrumentation will be required. Consequently, this framework briefly addresses the issues involved with employing general-purpose instrumentation at MSRs and fabricating custom instrumentation from compatible components. Much of the customization 
is either in the selection of compatible materials or in the selection of technology to avoid instrument exposure to the harsh fuel salt environment.

Different MSR concepts exhibit substantial design diversity, and the framework discusses the differences in instrumentation performance requirements due to the variance. As in other reactor classes, integral primary systems restrict measurement access at MSRs. Chloride and fluoride salts create different chemical environments, requiring different material choices for salt-wetted components. Fast-spectrum reactors tend to have much higher power densities, making in-core instruments more difficult to implement. Thermal-spectrum MSRs have in-core materials and structures similar to those of hightemperature gas-cooled reactors, so guidance is available on useful in-core instruments.

Most instrumentation at MSRs will not contact liquid salt. The high degree of MSR passive safety substantially reduces the number of safety-related instruments, and it completely eliminates the need for rapidly responding safety-related instrumentation. Much of the remaining safety-related instrumentation provides assurance that safety-related SSCs continue to be able to perform their functions, performs postaccident condition monitoring, or provides control room habitability monitoring.

High-temperature, radiation-tolerant commercial-grade instrumentation from other industrial processes can be widely employed at MSRs. MSR customized instrumentation technologies have been demonstrated to be adequate to operate MSR test reactors at prior molten salt test reactors for in-pile and out-of-pile salt loops, and for multiple specialized testing rigs. Instrumentation advancement needs to be focused on technological improvements to enable high-reliability, cost-effective, and long-lived plant operation on a commercial-scale.

Operations and maintenance automation was not a focus of the large, historic MSR development program. The greatest potential enhancement to MSRs is in the incorporation of new instrumentation technologies for maintenance automation that can be integrated into reactor operations. Modeling and simulation of maintenance and waste-handling activities will be especially important to ensure reliable, long-term operations.

The following prioritized list of MSR instrumentation development activities was taken from the body of the report:

1. Integration of maintenance planning and waste handling into reactor point designs to enable support for instrumentation development

2. Online salt and material coupon removal tooling

3. Instrumentation and cabling replacement tooling

4. Tooling for inspection of areas that are not readily observable

5. Online corrosion monitor development

6. High-temperature, salt-compatible gamma-thermometer development

7. Coolant salt ultrasonic flowmeter development

8. Fissile materials tracking planning to enable instrumentation evaluation

9. Fluoride salt activation flowmeter development

10. Online redox measurement capability development 


\subsection{HIGH TEMPERATURE FISSION CHAMBER: THE OHIO STATE UNIVERSITY SITE TEST PLAN}

Report: ORNL/TM-2017/448

High Temperature Fission Chamber: Ohio State University Site Test Plan

Report: ORNL/TM-2018/984

Commercial Prototype Design for a High Temperature Fission Chamber

Next-generation advanced nuclear reactors will require instrumentation designed to withstand higher temperatures and harsher environments. One instrument required to monitor power and in-core fuel management is a fission chamber. However, current fission chamber designs typically consist of a single wire surrounded by a stainless-steel housing lined with highly enriched uranium, backfilled with a methane- or nitrogen-doped fill gas. These materials and fill gases cannot withstand the higher temperatures and corrosive environments of high-temperature gas-cooled reactors or MSRs. ORNL had been developing a first-of-its-kind fission chamber using three concentric cylinders coated with a fissile material prior to the MSR FY 2018 campaign. Efforts continued in FY 2018 to build and test a prototype assembly.

When a neutron is absorbed by the fissile material, fission occurs, producing energetic fission fragments that split off and travel in opposite directions. The fission fragments travel into the gas region of the chamber and produce a path of ionized particles. A high voltage is applied to the cylinders of the chamber, causing the charged particles to drift to the oppositely charged electrode. The electronics detect the charges as pulses, where the rate of pulses is an accurate measure of the number of fission events, and thus reactor power. The High-Temperature Fission Chamber (HTFC) prototype and associated instrumentation was constructed and tested at The Ohio State University Research. Follow-on commercialization activities were begun based on the lessons-learned during the prototype construction.

\subsubsection{Experimental Results of the High-Temperature Fission Chamber Testing in a Harsh Environment}

Report: ORNL/TM-2018/802

Experimental Results of the High Temperature Fission Chamber Testing in a Harsh Environment

The HTFC prototype can operate in the harsher environments of advanced reactors. Materials compatible with these conditions but also efficient in conducting electrical current were selected for a prototype device. The HTFC and associated electronics were tested in The Ohio State University Research Reactor (OSURR) in October 2017. The goal of the experiment was to demonstrate that the HTFC can function over a range of conditions spanning high and low neutron flux, as well as high and low operating temperatures.

The Nextel sleeving, originally selected to help dampen mechanical vibrations inside the fission chamber, required preassembly heat treatment to remove organic additives. Without the treatment, the sleeving became conductive and formed a small electrical short inside the fission chamber, rendering the device inoperable. The device was disassembled, cleaned, and reassembled. Additional testing is expected.

\subsubsection{High-Temperature Fission Electronics}

Report: ORNL/TM-2018/991

Commercial Design of Custom Front-End Electronics for a High Temperature Fission Chamber

A high voltage applied to the HTFC cylinders of the fission chamber causes the charged particles to drift to the oppositely charged electrode. The electronics detect the charges as pulses, where the rate of pulses is an accurate measure of the number of fission events, and thus reactor power. Once the reactor reaches a 
steady power condition, the pulses overlap, and the output signal is a direct current signal. Four regions of operation for the fission chamber are

- low flux, low temperature and high temperature (pulse mode);

- $\quad$ high flux, low temperature and high temperature (current mode)

Because the fission chamber is designed to operate across a wide range of power, it needs to be able to acquire pulses and to monitor the current. The custom front end electronics were designed to operate in both modes and in all four regions. 



\title{
11. IRRADIATION TEST PLANNING AND INITIAL SALT IRRADIATIONS
}

\author{
Report: ORNL/TM-2018/954 \\ Evaluation of Flowing Salt Irradiation Facilities with High Neutron Flux
}

The primary containment of any MSR will be exposed to corrosive salt at high temperatures $\left(>650^{\circ} \mathrm{C}\right)$, which is a challenging design issue. Many MSR designs also use dissolved fuel, which introduces fission product-induced corrosion into the challenge. The effects of dissolved fission products (even at lower concentrations) must be taken into consideration.

At the most basic level, under both design and safety-basis conditions, the reactor primary containment and all components internal to the containment should (1) be resistant to salt corrosion, (2) maintain adequate strength under anticipated and off-normal conditions, and (3) be resistant to corrosion induced by entrained fission products. Experimental results will help establish the capability and lifetime of reactor materials and will facilitate the decision making of both the designer and the design authority. Much can and should be learned from out-of-pile testing; however, many of these concerns can only be addressed with irradiation testing.

Irradiation testing must encompass a wide variety of experimental facilities, including static capsules, natural convection loops, and pumped loops under low-flux and high-flux conditions, as well as appropriate temperature, flow, energy, and chemical composition. This document outlines existing and future capabilities for the most challenging subset of these experimental conditions: irradiation testing in a flowing loop under a high neutron flux.

A flowing loop design can be accomplished with an external flow loop that extends from the reactor core to an adjacent facility for pumping and heat exchange or with a cartridge loop, in which the entire experiment is self-contained, and the reactor's coolant provides the ultimate heat sink. There are advantages and disadvantages to either approach, but a cartridge-type experiment is strongly favored because of the challenges associated with uniformly melting salt and keeping it molten throughout the irradiation period.

For molten salt flowing loop experiments two challenges stand out: (1) the inability to use organic engineering materials such as O-rings to create seals between moving parts and (2) the lack of a commercially available molten salt pump that is small enough to fit inside a cartridge experiment and that does not use O-ring seals.

Fortunately, there is a history of molten salt flow loop experiments in the United States, and many of these problems are not new. A series of flowing loop experiments were reviewed, and the literature has been summarized. Two important considerations result from this literature review. First, there were many failures, unexpected leaks, and surprise results during this earlier irradiation campaign. As the current irradiation campaign begins, a new generation of tests, further challenges, and surprises should be expected. Second, the earlier campaign undertook a tremendous sustained effort to develop viable molten salt pumps. It is clear from their work that a priority for the current campaign should be to develop a miniature-scale pump that could be used in cartridge irradiation experiments as well as the large-scale pumps needed for reactor operation.

There are key parameters and design conditions that must be met in an experiment. The following is a short list of some key points to consider in any design of a flowing loop salt experiment.

- Pressure vessel. The primary experiment containment (i.e., the outermost experiment structure in contact with the reactor's primary coolant) typically must meet the American Society of Mechanical Engineers requirements for a pressure vessel during normal and off-normal conditions. 
- Internal heating. It will be necessary to have the loop molten and flowing before reactor startup and after reactor shutdown. The sudden insertion of heat during reactor startup, while the experiment is still solid, would likely lead to excessive containment stress due to differential thermal expansion between the salt and the containment. Even without radiation, the intermediate, partially melted phase would likely damage the pump. Also, some salts are known to disassociate when exposed to radiation at low temperature. For example, FLiBe has been shown to generate $\mathrm{F}_{2}$ gas when irradiated at temperatures below about $80^{\circ} \mathrm{C}$.

- Gap insulation. Currently, all steady-state high-flux research reactors are water cooled, with water coolant temperatures below $100^{\circ} \mathrm{C}$. This feature requires a gas or vacuum gap between the primary outer containment and the inner containment, which contains the salt. The insulation value of the gap can be set by the thickness of the gap and by the effective thermal conductivity of the gas. The effective thermal conductivity can be modified during irradiation by either mixing two gases with different thermal conductivities (e.g., helium and argon) or by pulling a vacuum in the gas space.

- Containment considerations. Organic compound-based parts, such as O-rings, cannot withstand the intense gamma irradiation associated with high neutron flux reactors for extended periods of time. Experiments must typically be sealed by welding, which may require the development of weld procedures. For the outer containment, the welds must meet pressure vessel standards.

- Utilities. The necessary utilities may vary by experiment, but they will typically include a supply of electrical power for heaters, pumps, and instrumentation; a gas supply for temperature and pressure control; a gas effluent system for fission product or off-gas analysis; instrumentation leads as required for the experiment; and chemistry control supply and return.

- Flexible leads. The utilities must be delivered to the experiment through many meters of smallgauge tubing. The leads are typically bundled together inside a mechanically flexible container tube. All the leads must be flexible enough to be moved into and out of position between cycles to allow for reactor maintenance and refueling.

- Seismic design. The top end of a cartridge experiment is usually of larger diameter and may cantilever some distance out of the core. The reactor safety analysis report will require the experiment designer to consider seismic loading on the assembly to make sure it can withstand any seismic incident that the reactor itself can withstand.

- $\quad$ Pump design. The pump design may be the most difficult aspect of the flowing loop. The pump must be capable of moving molten salt at $650^{\circ} \mathrm{C}$ to $800^{\circ} \mathrm{C}$ without significant operational degradation over the duration of the irradiation. Unless it is designed to be far removed from the core region (which may introduce cooling issues), the pump must be sealed without organic Orings. Since it will be sealed inside the containment, the pump mechanism should be as simple as possible to ensure reliability throughout operation. The pump must also fit inside the inner containment piping, which may only be 5 to $10 \mathrm{~cm}$ in diameter.

Several US reactors were identified as potential neutron sources for future salt experiments. The two national laboratory reactors, the High Flux Isotope Reactor, at ORNL, and the Advanced Test Reactor, at INL, are the most interesting because of their high flux capabilities, wide range of experiment sizes, depth of engineering capability, less restrictive limits on activity, and highly capable hot cells. However, there is a place for university reactors as well, especially in the development and testing phase of experimental assemblies.

University reactors at The Ohio State University and at the Massachusetts Institute of Technology were assessed. The Massachusetts Institute of Technology Reactor (MITR), a 6 MW light-water cooled and 
moderated research reactor, is operated by the Massachusetts Institute of Technology in Cambridge, Massachusetts. A cross section view of the MITR core is shown in Figure 4.

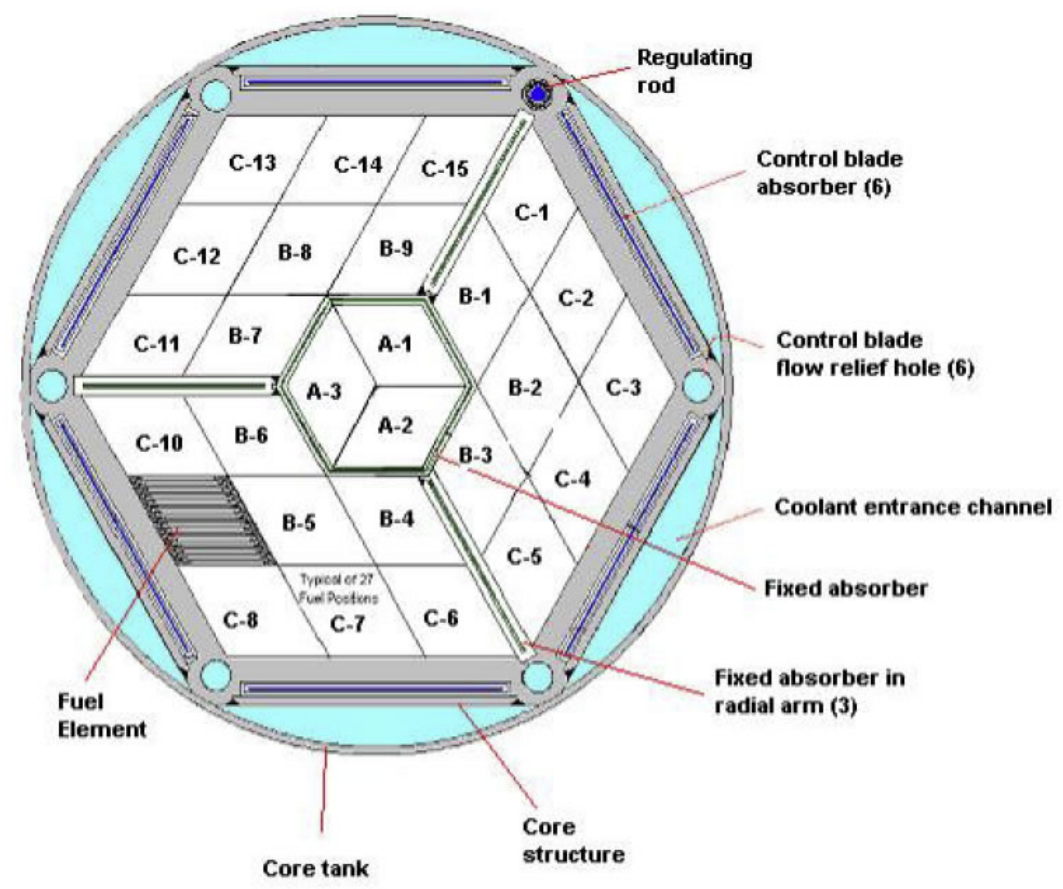

Figure 4. Cross-section view of the MITR core.

There are three in-core irradiation positions located in the center of the core in the A-1, A-2, and A-3 positions. An additional irradiation position exists in the graphite reflector (the 3GV facility).

Characteristics of the MITR irradiation positions are presented in Table 2.

Table 2. Characteristics of irradiation positions in the MITR

\begin{tabular}{lccc}
\hline \multicolumn{1}{c}{ Irradiation positions } & $\begin{array}{c}\text { Diameter } \\
(\mathbf{c m})\end{array}$ & $\begin{array}{c}\text { Thermal flux } \\
\left(\mathbf{( 1 0}^{\mathbf{1 4}} \mathbf{n} / \mathbf{c m}^{\mathbf{2}} \mathbf{s}\right)\end{array}$ & $\begin{array}{c}\text { Fast flux (1 MeV Eq.) } \\
(\mathbf{1 0}\end{array}$ \\
\hline In-core (3 are available) & 4.57 & 0.36 & 1.2 \\
Graphite reflector (3GV) & 7.62 & $0.04-0.1$ & --- \\
\hline
\end{tabular}

A series of molten salt experiments have been conducted in the in-core position where measurements of corrosion and tritium transport were made on $\mathrm{SiC} / \mathrm{SiC}$, and metal coupons were irradiated in liquid FLiBe salt for the High Temperature Fluoride Salt Reactor.

The OSURR is a pool-type reactor located on the campus of The Ohio State University in Columbus, Ohio. It is licensed to operate at thermal powers up to $0.5 \mathrm{MW}$, with an active fueled length of $38 \mathrm{~cm}$. The OSURR is operated on demand, which makes it ideal for short-term irradiations.

Three irradiation positions are available within the core grid, each consisting of a dry tube that extends from the top of the pool to a position in the core grid. Moveable vertical dry tubes with diameters of 17.8 cm (7 in.) and $25.4 \mathrm{~cm}$ (10 in.) are available for placing experiments at or near the core boundary. A summary of the size and neutron flux for these irradiation positions is presented in Table 3. 
Table 3. Characteristics of selected irradiation positions in the OSURR.

\begin{tabular}{|c|c|c|c|}
\hline Irradiation positions & Diameter (cm) & $\begin{array}{l}\text { Thermal flux } \\
\qquad\left(10^{14} \mathbf{n} / \mathbf{c m}^{2} \cdot \mathbf{s}\right)\end{array}$ & $\begin{array}{r}\text { Fast flux (1 MeV Eq. }) \\
\left(10^{14} \mathrm{n} / \mathrm{cm}^{2} \cdot \mathrm{s}\right)\end{array}$ \\
\hline Central Irrad. Fac. (CIF) & 3.30 & 0.14 & 0.047 \\
\hline Auxiliary Irrad. Fac. (AIF) & 6.22 & 0.045 & 0.026 \\
\hline Peripheral Irrad. Fac. (PIF) & 6.35 & 0.031 & 0.012 \\
\hline $\begin{array}{l}\text { Moveable dry tubes ( } 7 \text { in, } 10 \\
\text { in) }\end{array}$ & $16.5,24.1$ & 0.011 & 0.02 \\
\hline
\end{tabular}

The large-diameter facilities in OSURR allow for larger-scale experiments, which is an advantage for flowing loop tests. The relatively low neutron flux is not conducive to high-fluence experiments, but it may be an ideal test bed for testing cartridge loop technology in a facility with easier access than that of a national laboratory. OSURR can accept fueled salt, but the post-irradiation handling limits may restrict the fuel loading and burnup to relatively low levels.

\subsection{FIRST SALT IRRADIATIONS}

The MSR campaign supported a first-of-a-kind molten salt corrosion test at OSURR. ORNL recently completed a high-temperature fission chamber test at the OSURR with a furnace capable of achieving $800^{\circ} \mathrm{C}$ and an internal volume compatible with existing molten salt experiments. This infrastructure was used to perform a low-cost irradiation of material specimens in chloride salts. The experiment tested stainless steel and Alloy $\mathrm{N}$ specimens in a chloride salt at $800^{\circ} \mathrm{C}$ under irradiation conditions. ORNL has already been conducting unirradiated chloride salt corrosion tests, and the irradiated specimens will be compared with unirradiated specimens in the same salt and temperature exposure. This is the first molten salt irradiation experiment conducted by ORNL in many decades and establishes an affordable, reusable capability for future corrosion experiments. 